\title{
On The Aesthetic Value of Dance Art in the New Period
}

\author{
$\mathrm{Na}$ Yue \\ Normal College, Xi'an University, Xi'an, Shaanxi, PR, China 710065
}

Keywords: Dance art; Aesthetics; Value; Judgment

\begin{abstract}
Dance is a form of expression, which has a strong artistic value and aesthetic value .Under the condition of market economy, the dance works could be called a kind of special commodity which have economic value 、 social value and aesthetic value. In the new historical period, if we want to create excellent works of dance, we should unify the works of aesthetic value and economic value, and constantly explore the aesthetic value of dance art and strive to its aesthetic value and economic value of organic integration.

Art is the beauty of labor creation, art is the beauty of labor products, artistic beauty is based on the understanding of real life and the desire for a better life. Dance art is the performing arts. It is different from painting, calligraphy, photography, it is to be performed through the completion of the art. Emphasis on the use of dance skills to show the artistic performance of art, the artistic conception of art, the creation of artistic image. Dance is one of the earliest art forms created by mankind, which originated from the joy and madness of mankind's discovery of the body's initiative and beauty ${ }^{\text {(11 }}$. Beauty in life, beauty in the heart. Beauty is also the most fundamental and important factor of dance art. Dance and other art forms, but also a kind of social ideology, China Dance Aesthetics, since ancient times has the simple materialism.

The distinction between dance and other forms of art is obvious, and it is based on the human body as a basis for performance ${ }^{\mathbf{I 2}}$.Dance performers will dance perfect show through their own body language, in this dance to express the content is the main body, rather than the person itself. Dance through the body movement, to become a way of artistic expression, which must be closely linked with people's aesthetic consciousness.

Emotional factors play an important role in people's aesthetic standards, and it depends on the people's thoughts .

Intuitive state is easy to determine people's preferences. Aesthetic activity is a complex psychological process, which includes both intuitionalist and logical judgment.

The pursuit of beauty can be said to be a human nature, but not everyone can accurately express their aesthetic point of view ${ }^{\mathbf{I} 3 \mathbf{1}}$.Aesthetic is the result of the interaction between nature and human, subject and object, and it is the satisfaction of certain aesthetic attribute of aesthetic object to certain aesthetic subject's aesthetic need. Aesthetic value refers to aesthetic research can not leave the reality of human aesthetic activities and to start an independent theoretical system.

Art can be understood as a special social ideology. It will have an impact on people's life, work and so on, and ultimately inspire and motivate people's all-round development ${ }^{\text {(41 }}$. The creation of aesthetic value of dance art, to create the main body through the dance itself to shape the image of art, through this specific image of the main expression of the aesthetic feelings and a specific understanding of beauty. The process of creation of dance works is an aesthetic process in itself, because in the process of creating the works, the first is a test of their aesthetic standards ${ }^{\text {I5I }}$. The dancers communicate with the experiencer through emotion and cognition. The cognitive value of dance art is often shown as enlightenment and understanding, and the value of education is subtle. The emotional value is the sublimation of purification. The contemporary dance art with the aesthetic values as the core, not only realize the aesthetic value of dance, but also affected the people's mental outlook and aesthetic concept through the process of artistic production ${ }^{\mathbf{6} 6 \mathbf{1}}$.
\end{abstract}

\section{The Evaluation of Aesthetic Value of Dance Art in the New Period.}

Art is always born in the specific period, each piece of art works often has the brand of The Times ${ }^{61}$. 
Under the tide of commodity economy, the dance work has the property of the goods. Dance works contains both commodity value into the aesthetic value.

Dance is a special art form, but also satisfies the basic demands of all arts. In the dance art, we first consider the value itself is the art of dance, and non-commercial properties ${ }^{\mathbf{l} 8 \mathbf{1}}$. This is the basis of support dance this art, different from other commercial properties of the product. The creation of dance works, aesthetic value and social reality, the contradiction between commodity value and social reality from time to time.

The creation of works of art is done in the middle of contradictions. The creation of dance art creators is the starting point of the whole production of art, the creator must fully consider various contradictions, to grasp the various stages in the conflict should solve the main contradiction, it directly decides the success or failure of dance art socialized production stage.

Art and commodities although are not split, but after all, has its own unique properties ${ }^{\mathbf{1 9 1}}$. A work of art even under the influence of commodity production consciousness, and is restricted by the law of value, but the value of it is difficult to define ${ }^{\mathbf{r} 10 \mathbf{1}}$. More depends on its value system of the aesthetic value of art, a work of art is only a high degree of aesthetic value, can have the goods value. Under the condition of market economy, under the premise of in promoting spiritual civilization, we consider a work of art, should regard it as more of a spiritual production. But unfortunately, we have a lot of literary and art workers think dance works of aesthetic value is mainly dependent on its economic value, for the view of this kind is a form of myopia and ignorant behavior, this excessive pursuit of commercial profits behavior in the end, often received the opposite effect. We should respect the law of value in the process of production of art, but not by the sacrifice of beauty and art, should not directly apply the economic benefit of scale to measure the intrinsic value of art.

In the present, there is a trend that the use of high technology means to weaken the thinking in the process of artistic creation, organization and the processing procedure. This view only theory of technology exaggerated the function of high technology in the art processing. Art, originated from thought at first, not for the beauty of cognitive and feeling, it is a good science and technology means just a simple superposition, even there is no point in terms of aesthetic feeling. People's main body status is unshakable in the art creation.

The art of dance is higher than life and come from life. The dance art's popularity and influence the deepest level is still the masses. The masses love for dance to make the dance has broadness for existence and also make it with the commodity attribute.

In the process of dance creation, we should pay more attention to market, but also can't be bound by the market. Because the market started opening. We can not give up the own of art's personality, style, taste, depth and other factors to blindly cater to the market.

Dance works is not only an unalloyed consumable, but also an ideological art which can show many complex emotions of people.

The intention of the dance through the language and the overall image of dance to reveal an inner angry, emotion, spirit, strength of character and mind. As is we all known the beauty of implication. Generally speaking, the implication of art is not entirely reflected the theme of the thought by the dance image. It's a thing that more metaphysical than the theme and the basic reason why the best dance with immortal artistic charm.

With the advancement of globalization steps, we are supposed to break the original barriers meet the different artistic styles with open inclusive attitude. Dance works should absorb nutrients from the different literary forms. Although there are limits in different forms of art, itself is a miscibility. This combination is not a careless organization without guidelines. We should stick to the soul of an art form in itself, and to push its development. Any different kinds of art can't be changeless. The future of humanity and the country's prosperity depend on the innovation and application of knowledge at any time. As the dance art, playing a role in the construction of spiritual civilization, we must make it constantly updated based on the concept of dancers. Especially the choreographers need to enrich the knowledge. Without cultural knowledge, obtaining high-quality goods only from the ontology is not enough. Innovation are based on the accumulation of knowledge and the 
cultivation of talents at first.

The Influence of Aesthetic Value Judgment on the Dance Art. Every form of art has its own spiritual quality, every form of art is constantly moving forward. In the new historical period, only through the discussion of the nature's value of dance art, can we have a clear understanding about the trend and the judging criteria of the dance works, meanwhile, can we make the dance art faster and better development, what's worse, can the majority of the audience through the image of dance art understand its artistic quality, deep into its value system and feel the real value of the dance.

Dance art is the product of human material civilization and spiritual civilization. Under the background of today's ideological pluralism, dance art form and creative ideas all appear the feature of colorful and multidimensional expansion. Dance art in the new historical period, continue to maintain a strong vitality and strong contemporary style. It is inevitable that people will judge the dance with the characteristics of the times, meanwhile it is also restricted by the unique view of dance history and the aesthetic taste of dance.

Evaluation of dance is the reverberation of dance works among the masses. Review of dance is about specific dance works of creation and performance of review activities. Scientific review of dance should not only actively find outstanding works, and excellent professional talents, points out that its essence, the main, and sometimes even the author is unclear shortcomings, let people obtaining aesthetic enjoyment and thought enlightenment. Evaluation of dance is the main task of the thoughts and art analysis of specific works of dance, to make objective evaluation, so as to improve the audience's appreciation and identification of dance art, reveals a particular appreciation object is different from other object's artistic personality. Contemporary dance art theme review correct developing direction of the dancing art. In the review of the dance should actively carry out the policy of "Let a hundred blossom and a hundred schools of thought contend." On the one hand, to promote various theme, genre, form, style of dance creation prosperity and development. On the other hand, through the different art advocates, art evaluation of freedom to discuss, improve the level of dance creator's thoughts, art and the masses of the dance cultural knowledge and art appreciation level and so on. People with a certain aesthetic viewpoint, to analyze and identify dance phenomenon in social life and the reviews of a kind of scientific research activities, which is the most active part in the dance. Scientific and profound review of dance, can play the lead role in the development of dance. During evaluation of works. Whether full of aesthetic feeling must be put in important position.

Therefore, the admission of dance review not only tells people how to generally recognize the true or false, good or bad, beautiful or ugly works, but also makes accurate and convincing analysis and judgment on the works and dance thoughts, and makes specific analysis and scientific comments on the composition of the content and form of the various factors.

Human civilization can not be separated from the cultural heritage, but usually we put the culture

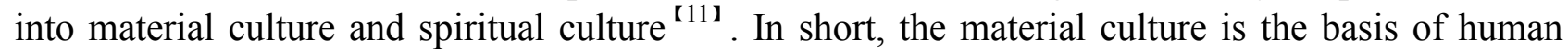
survival, the most basic conditions for human life, and spiritual culture is the survival of human beings and the way to improve their own reflection on people's ideology. There is no doubt that dance is an art category in the field of spiritual culture. The art of dance to transcend aesthetic activities to cultivate people's mind and create a life beyond the realm of people, give people an open-minded attitude toward life. To play the social value of the art of dance, the purpose is to promote the progress of social civilization, the construction of advanced culture, the function of art to inspire people, unite people, educate people, serve the people. Dance art world is magnificent and colorful, to lead the modern fascination with it, must be assigned to it to the modern consciousness of charm, promote social, rational and realistic things, signal into aesthetic pleasure of life and emotion, make it become a good memory of human beings, become people a kind of temperament, Tao Zhi aroused free emotional catharsis in the aesthetic field of joy. 


\section{Reference}

[1] Ye Jibin $<$ On the dynamic realization of aesthetic value in the process of art reception>, $<$ Jianghuai tribune $>, 2000$ fourth.

[2] Zhang Yuneng < Hiller's thought of Aesthetic Anthropology $>$, Guangxi Normal University press, 2005 Edition.

[3] Niu Qingqing < Study on Han nationality yangko dance and modern aesthetic consciousness>, $<$ Qinghai Social Sciences $>, 2005$ fourth.

[4] (4)_Liu Qingge $<$ The conflict and integration of eastern and Western dance culture $><$ Journal of Beijing Dance Academy>, 2000 first.

[5] Zhao Daofei,Lu Yangqiu <Aesthetic education and art appreciation>, Southeast University press,2007 Edition.

[6] Liu Guilan <The development trend of folk dance culture in the period of social transformation $>$, <Qinghai Social Sciences $>, 2007$ second.

[7] Li Lanwei <The development trend of folk dance culture in the period of social transformation $>$, < Journal of Minzu University of China $>, 2000$ third.

[8] Wu Huilian <The development trend of folk dance culture in the period of social transformation $>$, <Education Art $>, 2005$ twelfth.

[9] Yi Xiaohui Some thoughts and Research on digital dance [J] Popular literature and art,2012,(22):112

[10]Liu Li On the history, characteristics and prospects of digital dance [J] Journal of Beijing Dance Academy,2009,(2):111-115.

[11]Tang Yanxin New dance of science and technology_-Digital dance [J] Chinese Journal(middle of the Journal),2012,(10):142. 